\title{
Control of facies and fluid potential on hydrocarbon accumulation and prediction of favorable Silurian targets in the Tazhong Uplift, Tarim Basin, China
}

\author{
Yu Yixing, Chen Dongxia*, Pang Hong, Shi Xiuping and Pang Xiongqi \\ State Key Laboratory of Petroleum Resources and Prospecting, China University of Petroleum, Beijing 102249, China \\ (C) China University of Petroleum (Beijing) and Springer-Verlag Berlin Heidelberg 2011
}

\begin{abstract}
Exploration practices show that the Silurian hydrocarbon accumulation in the Tazhong Uplift is extremely complicated. Our research indicates that the oil and gas accumulation is controlled by favorable facies and low fluid potential. At the macro level, hydrocarbon distribution in this uplift is controlled by structural zones and sedimentary systems. At the micro level, oil occurrences are dominated by lithofacies and petrophysical facies. The control of facies is embodied in high porosity and permeability controlling hydrocarbon accumulation. Besides, the macro oil and gas distribution in the uplift is also influenced by the relatively low fluid potential at local highs, where most successful wells are located. These wells are also closely related to the adjacent fractures. Therefore, the Silurian hydrocarbon accumulation mechanism in the Tazhong Uplift can be described as follows. Induced by structures, the deep and overpressured fluids migrated through faults into the sand bodies with relatively low potential and high porosity and permeability. The released overpressure expelled the oil and gas into the normalpressured zones, and the hydrocarbon was preserved by the overlying caprock of poorly compacted Carboniferous and Permian mudstones. Such a mechanism reflects favorable facies and low potential controlling hydrocarbon accumulation. Based on the statistical analysis of the reservoirs and commercial wells in the uplift, a relationship between oil-bearing property in traps and the facies-potential index was established, and a prediction of two favorable targets was made.
\end{abstract}

Key words: Tazhong Uplift, Silurian, control of facies, fluid potential, oil and gas prediction

\section{Introduction}

The Silurian Formation in the Tarim Basin covers an area of $24.9 \times 10^{4} \mathrm{~km}^{2}$, with only the middle and upper parts of the Silurian Formation being well preserved in the Tazhong Uplift, including the Yimugantawu, Tataaiertage, and Kepingtage Formations from top to bottom. There are 55 wells drilled through the Silurian Formation in the Tazhong Uplift, with seven producing commercial oil flow, seven producing little oil and most producing asphalt or viscous oil (Hu et al, 2005). Five reservoirs have been discovered, Tazhong 10, Tazhong 11, Tazhong 47, Tazhong 12, and Tazhong 169. Exploration has shown that generation in multiset source rocks, multiple expulsion of hydrocarbon, multistage accumulation, and destruction of reservoirs result in complicated patterns of hydrocarbon accumulation (Sun et al, 2007; Li et al, 2008; Zhou et al, 2009). Previous studies suggest that quite a few factors control the Silurian oil-

*Corresponding author. email: lindachen@cup.edu.cn Received September 18, 2009 gas distribution and accumulation in the Tazhong Uplift. Besides the hydrocarbon source kitchen (Sun et al, 2007), both structure and lithology are significant factors in the hydrocarbon accumulation in the uplift ( $\mathrm{Lü}$ and $\mathrm{Hu}, 1997$; Liu et al, 2007). Paleo-uplifts and paleo-slopes play a role in the spatial distribution of oil and gas in the central Tarim Basin (Sun et al, 2007). To be more specific, the vertical distribution is controlled by caprocks (Hu et al, 2005) while the horizontal distribution is closely related to faults ( $\mathrm{Li}$ et al, 2007). The development of local structures (faults, fractures and folds) and various combinations of reservoir rocks and caprocks is also a key factor for petroleum formation in the uplift (Sun et al, 2007; Lü et al, 2008). Exploration activities show that petroleum is distributed across a large area, but no big field has been discovered, which indicates very complicated traps. For instance, 16 wells were drilled in the Tazhong 47-12 zone, and only six produce a commercial oil flow. Analysis shows that the failure results from the fact that hydrocarbon accumulation in this region is controlled not only by structural factors, but also by distribution of sand bodies, physical properties of reservoir rocks, and the 
transport systems. We use the theory of facies-potential controlling hydrocarbon accumulation (Pang et al, 2007) to study the geological characteristics in the central Tarim Basin, establish a relationship between petroleum-bearing property in traps and facies-potential index (FPI), and predict favorable exploration targets.

\section{Facies-controlled hydrocarbon accumulation of the Silurian in the Tazhong Uplift}

"Facies" was first introduced into geological literature by the Danish geologist Steno and was applied to the study of sedimentary rocks by Gressly (Gressly, 1838). Afterwards, researchers presented such concepts as tectonic facies (Hsu, 1991; Xu et al, 1994; Robertson, 1994), lithofacies (Miall, 1990) and petrophysical facies (Spain, 1992; Xiong et al, 1994). Facies can be divided into four macro-to-micro levels, tectonic facies, sedimentary facies, lithofacies, and petrophysical facies, which play different roles in hydrocarbon accumulation. Tectonic and sedimentary facies are macro factors, and control the location and size of reservoirs. Lithofacies and petrophysical facies are micro factors, and control the heterogeneity and petroleum-bearing property within the reservoirs (Pang et al, 2007; Chen et al, 2008).

\subsection{Control of tectonic and sedimentary facies on macro hydrocarbon distribution}

The macro distribution of Silurian oil and gas in the Tazhong Uplift is controlled by tectonic facies and sedimentary facies. Influenced by N-S and E-W fracture systems, the central Tarim Basin has northern and southern belts, and eastern and western blocks. From north to south, there are the Tazhong 1 Slope Break Belt (including the inside and outside belts), Tazhong 10-16 low structural zone, central fault horst belt, northern slope, eastern buried hill, and southern slope (Fig. 1). The discovered Silurian oil and gas is mostly in anticline reservoirs (e.g. Tazhong 11, Tazhong 47, Tazhong 12 and Tazhong 10), and stratigraphic-lithologic reservoirs (e.g. Tazhong 162), which are mainly distributed along the Tazhong 10-16 low structural zone. The wells which have oil shows are mostly located in the east and west of the Tazhong 1 Slope Break Belt and central fault horst belt, and few discoveries have been made in the northern slope, eastern buried hill, and southern slope. Therefore, the Silurian hydrocarbon distribution is dominated by ancient and modern structural patterns.

The Silurian sedimentary environment in the Tazhong Uplift was a tide-controlled shore with mainly tidal flat sedimentary systems, including tidal zones and subtidal zones, where micro-facies such as mud flats, mixed flats, sand flats, tidal channels and subtidal channels are developed. An

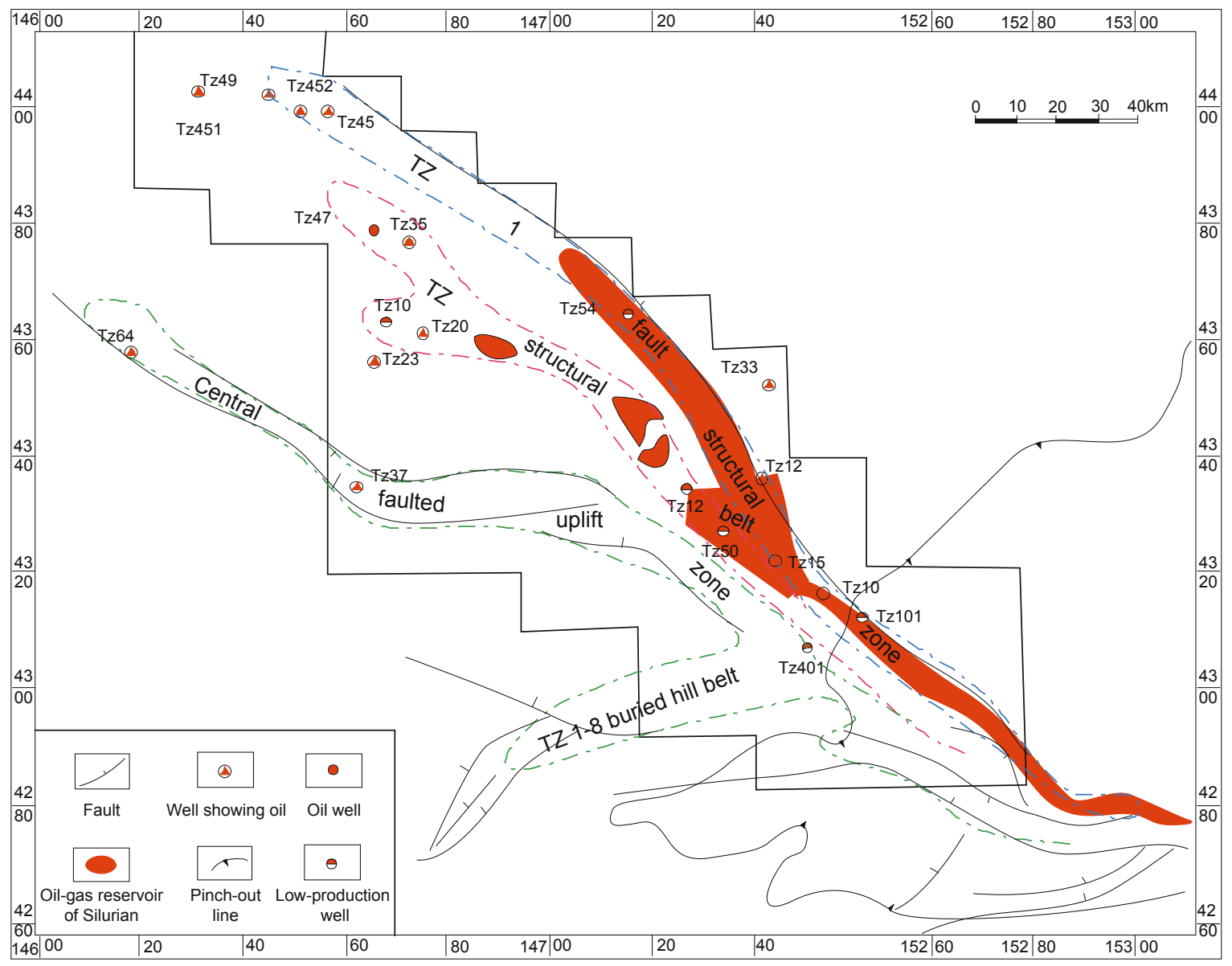

Fig. 1 Division of structures and the Silurian hydrocarbon distribution in the central Tarim Basin 
analysis of the relation between sedimentary environments and petroleum show during drilling indicates that reservoir distribution varies with different environments. High-energy zones are favorable for hydrocarbon accumulation and reservoir formation. Reservoirs and wells showing oil and gas in this area are mostly located in low tidal flats and tidal channels on tidal zones, with very few wells in mixed flats (Fig. 2).

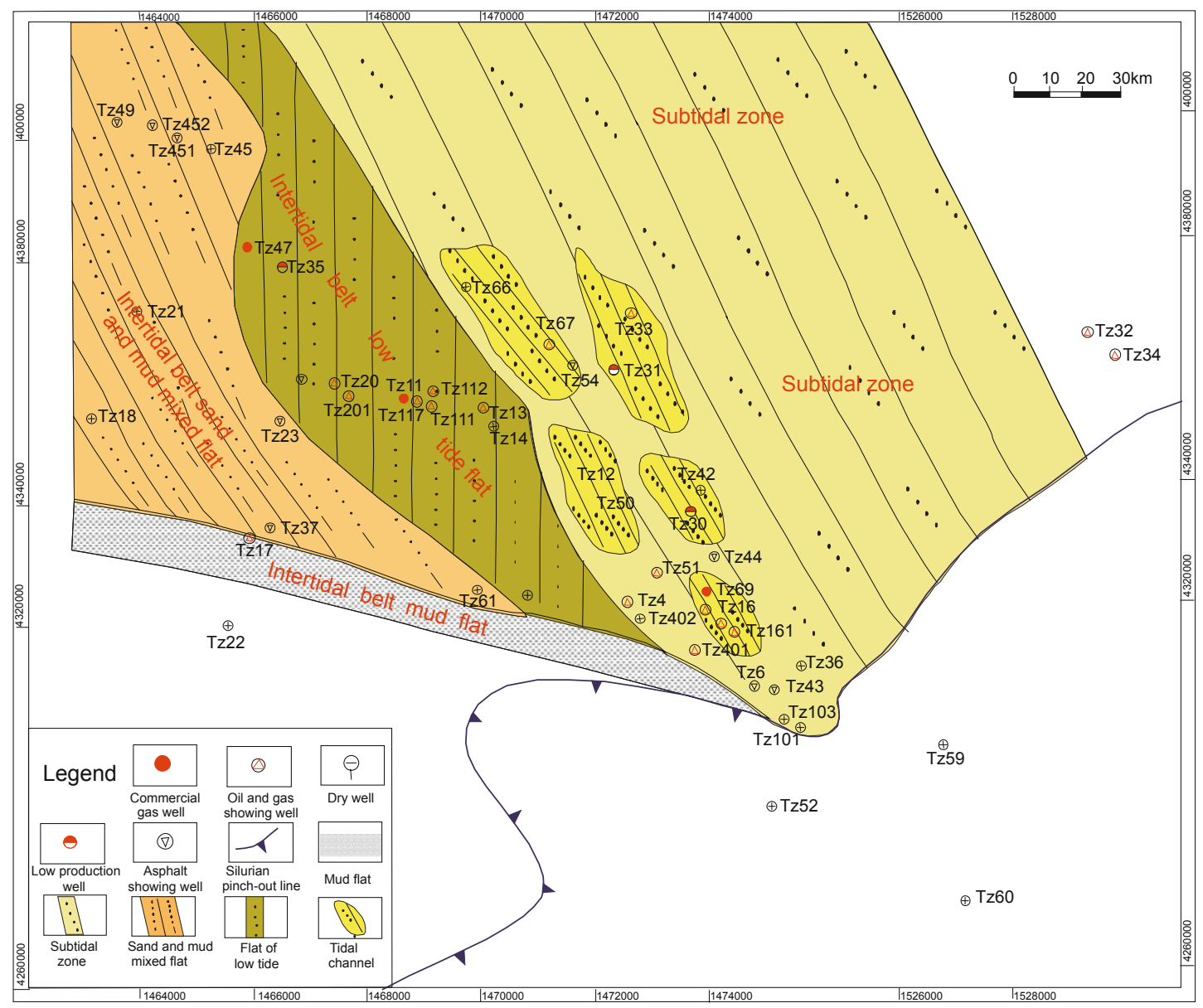

Fig. 2 Sedimentary facies of the upper section of the Silurian Kepingtage Formation in the central Tarim Basin

\subsection{Control of lithofacies and petrophysical facies on the petroleum-bearing property within sand bodies}

The petroleum-bearing property within Silurian sand bodies in the Tazhong Uplift is controlled by lithofacies and petrophysical facies. Exploration activities show that the mud flats, which consist mostly of mudstones mixed with silty mudstones, hardly display any oil and gas. The sand flats, which are mainly composed of fine-grained sands, and the tidal channels, consisting mostly of medium and fine-grained sands, are the main reservoirs in the uplift. Statistics indicate that over $90 \%$ of the petroleum discovered is distributed in the silty and fine-grained sandstones, while the remaining $10 \%$ is distributed in reservoirs consisting of conglomeratic sands. The average diameters of grains in the reservoirs range from 0.1 to $0.5 \mathrm{~mm}$. Most reservoirs are tidal channels and sand flats, with the sorting ranging from medium to mediumgood, and the grain roundness from sub-edge to sub-round. The physical properties of tidal channels and sand flats are also good, with porosity ranging from $6 \%$ to $18 \%$, and permeability of (0.01-46.90) $\times 10^{-3} \mu^{2}$ (Zhao et al, 2007). The petroleum-bearing property within sand bodies is also controlled by the physical properties and heterogeneity of the reservoirs. Taking the Tazhong 12 well as an example (Fig. 3), the relationship between reservoir properties and saturation was analyzed. High porosity and permeability indicates good petroleum-bearing property while low porosity and permeability indicates poor petroleum-bearing property (Fig. 4). The two fault-anticlines, Tazhong 35 and 47, in the Tazhong 10 structural zone are both located in the high position. The Silurian reservoirs in the Tazhong 35 well zone do not develop oil-bearing traps because of very low porosity of only $8.9 \%$. However, the Silurian reservoirs in the Tazhong 47 well zone develop oil-bearing traps due to the porosity ranging from $10 \%$ to $17 \%$. A statistical analysis of the Silurian reservoirs reveals that almost no oil or gas has been found in a clastic reservoir with porosity lower than $6 \%$ or permeability less than $1 \times 10^{-3} \mu^{2}$. Most oil and gas wells are found in reservoirs with porosity between $6 \%$ and $20 \%$ or permeability ranging from $0.5 \times 10^{-3} \mu \mathrm{m}^{2}$ to $100 \times 10^{-3} \mu^{2}$ (Figs. 4 and 5). The oil saturation in the reservoirs is between $45 \%$ and $65 \%$, and increases with an increase of porosity or permeability. Within a reservoir, no oil can be found when the porosity is lower than $6 \%$ or the permeability is less than $0.5 \times 10^{-3} \mu \mathrm{m}^{2}$ (Fig. 4). 


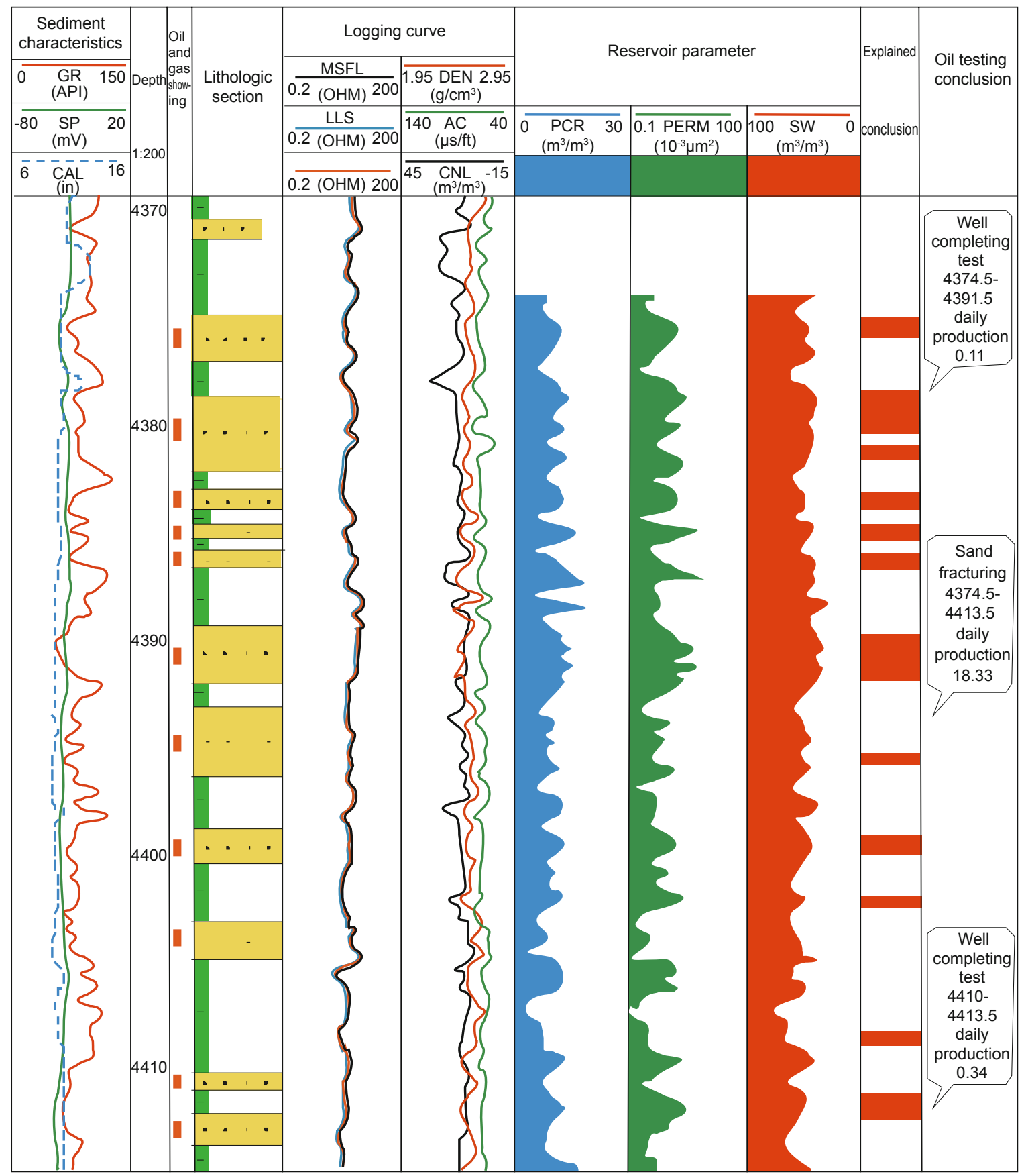

Fig. 3 Reservoir characteristics of the TZ 12 well

\subsection{Model of facies-controlled hydrocarbon accumulation}

Favorable facies and high porosity and permeability controlling the hydrocarbon accumulation is a basic feature of the distribution of petroleum-bearing basins in China. "Favorable facies" refer to the rocks favorable for hydrocarbon accumulation, whose grain diameter ranges from 0.1 to $0.5 \mathrm{~mm}$, mainly consisting of silty and fine-grained sandstones. High porosity and permeability is a relative term which means that the threshold values of porosity and permeability for favorable reservoirs decrease as the burial depth increases (Fig. 5). Statistics of physical properties of the clastic reservoirs at depths from $3,600 \mathrm{~m}$ to $4,800 \mathrm{~m}$ in the central Tarim Basin show that from 3,600 $\mathrm{m}$ to 3,800 $\mathrm{m}$, the threshold porosities range from $9 \%$ to $10 \%$ while the threshold permeabilities range from $4 \times 10^{-3} \mu \mathrm{m}^{2}$ to $10 \times 10^{-3} \mu^{2}$. Below $4,200 \mathrm{~m}$, the threshold porosities fall to $6 \%-8 \%$ and the threshold permeabilities fall to $(0.5-1) \times 10^{-3} \mu \mathrm{m}^{2}$. The porosity and permeability values of over $96 \%$ wells which have oil and gas shows are higher than the threshold values, which suggests a geological model of reservoirs controlled by relatively high porosity and permeability.

\section{Control of potential on Silurian hydrocarbon accumulation in the Tazhong Uplift}

Hubbert (1953) and England et al (1987) proposed the 

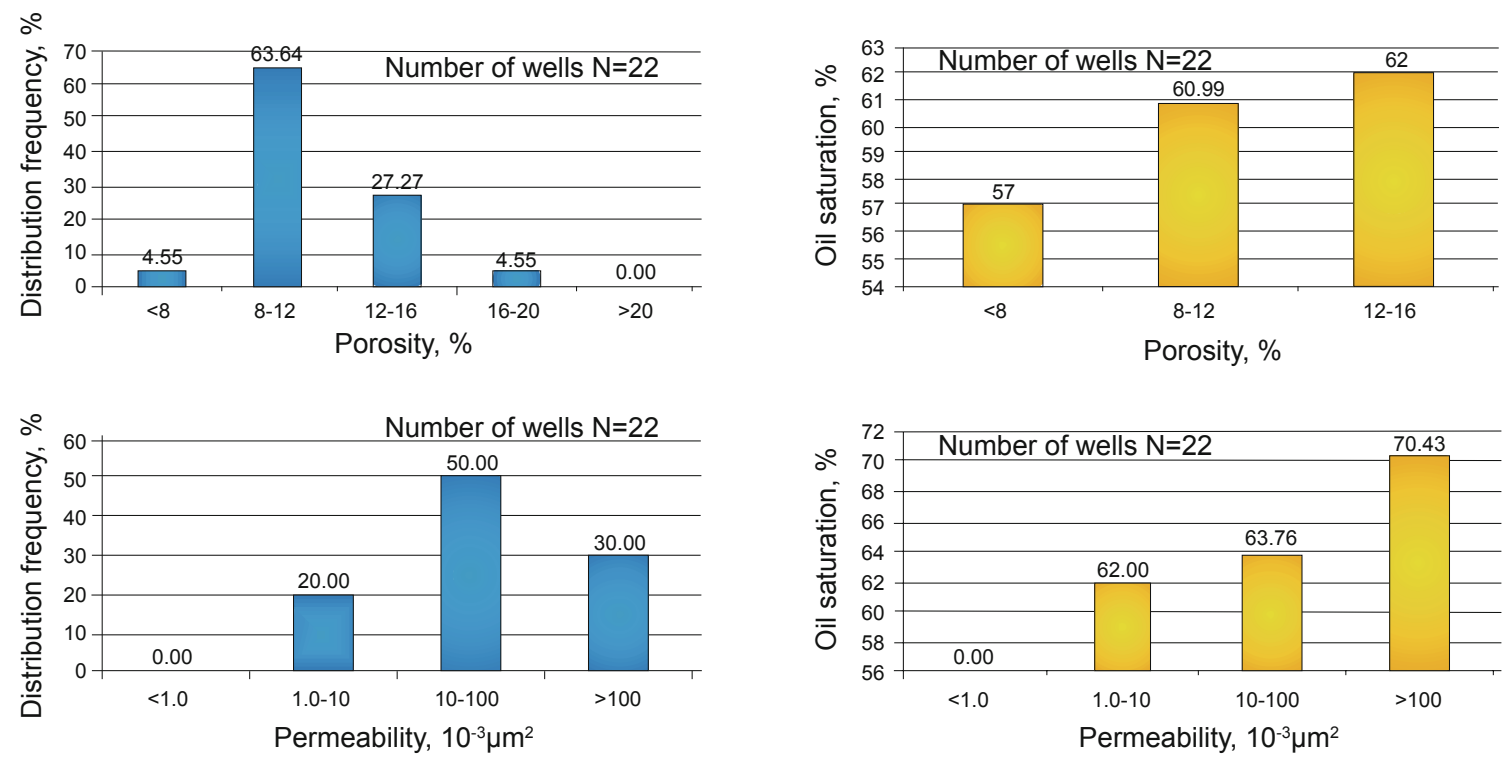

Fig. 4 Statistics histogram showing the physical properties and oil-bearing property of the Silurian reservoirs in the central Tarim Basin

Porosity, \%

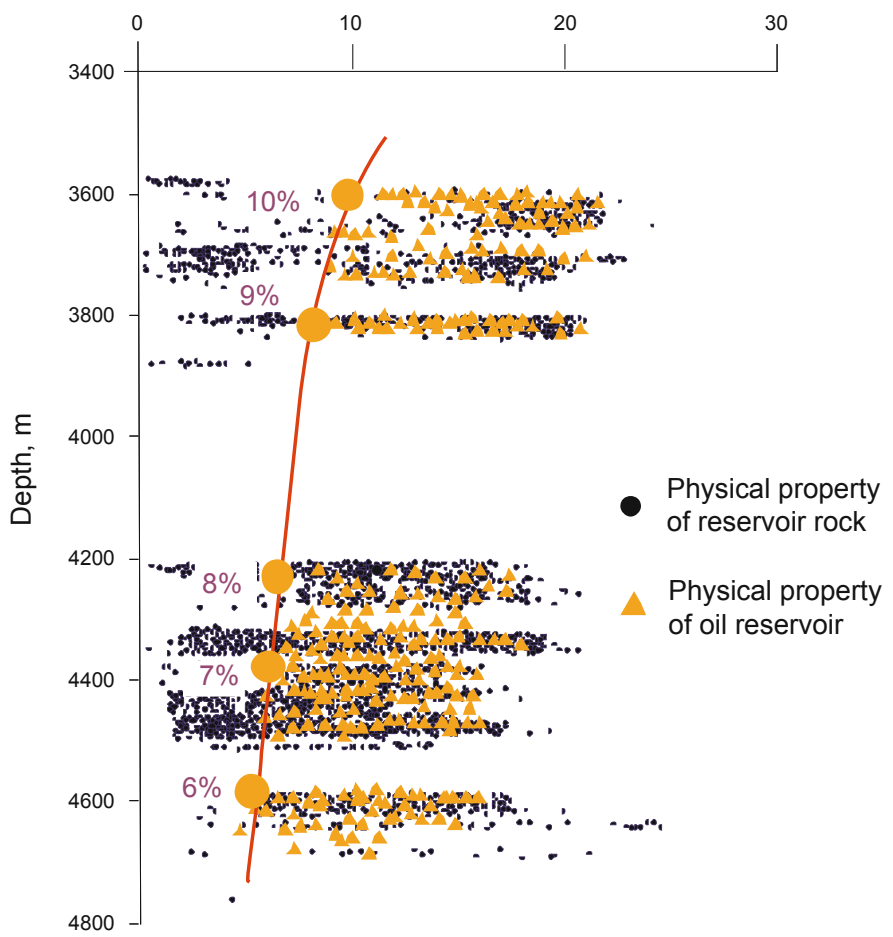

The critical porosity of oil reservoir
Permeability, $10^{-3} \mu \mathrm{m}^{2}$

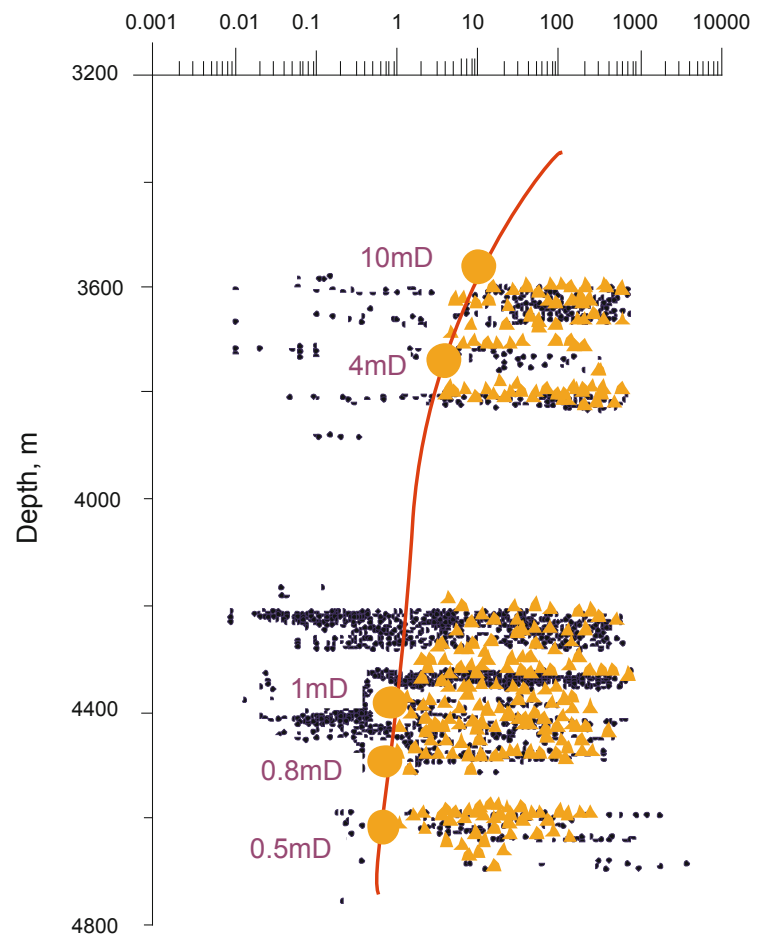

The critical permeability of oil reservoir

Fig. 5 Distribution characteristics of physical properties of Silurian reservoirs in the central Tarim Basin

concept of fluid potential and a model for its theoretical calculation, which has become a widely accepted way for quantitative description of hydrocarbon migration and accumulation (Dahlberg, 1982; Chapman, 1982; Hindle, 1997). As early as 1998, Wang and Chen used the fluid potential theory to study the conditions for hydrocarbon migration and accumulation in the Manjia'er Depression and adjacent areas in the Tarim Basin. They pointed out that the enclosed or half-enclosed low-potential zones are the most favorable for hydrocarbon accumulation because they can accept oil and gas formed under various conditions. It is found that buoyancy force, abnormal fluid pressure, hydrodynamics and capillary pressure control hydrocarbon migration and accumulation and reservoir formation (Berg, 
1975; Levorsen, 1967). Since different forces play different roles in hydrocarbon accumulation, the fluid potential can be divided into four types, corresponding to the four geological agencies: potential energy, pressure energy, interfacial energy, and kinetic energy (Pang et al, 2007). The Silurian reservoirs in the Tazhong Uplift are mainly structural pools, so they are mainly controlled by potential energy and pressure energy.

\subsection{Control of potential energy on hydrocarbon accumulation}

Buoyancy force always leads fluids upwards to the structural high point. Calculation of gravitational potential energy indicates that the structural high point where the fluids stop is a place with low potential energy. In other words, the direction in which the potential energy decreases is exactly the direction in which hydrocarbon migrates and accumulates. Therefore, the low potential energy location corresponds to the relatively low potential location in a structural high point. Superposition of the Silurian structural map and reservoir distribution map in the central Tarim Basin shows that the distribution of anticline pools are closely related to the high point of local structures (Fig. 6). To be specific, the anticline pools in this area are not distributed along the shallow layers or margins of the basin, but in the low structural zones of Tazhong 10-16, including Tazhong 10, Tazhong 11, Tazhong 47, Tazhong 12 and Tazhong 50. The distribution of anticline reservoirs in this area suggests that, in spite of a general trend of the hydrocarbon moving upward to the shallow layers, the local structural high point is the dominant factor because of its relatively low potential. There are 16 wells drilled in the Tazhong 47-12 area, and ten wells produce commercial oil flow, at a success rate of $62.5 \%$, including four in the Carboniferous and six in the Silurian. It can be seen that the reservoir distribution in this area is mainly controlled by local structures, and all the successful wells are located at local structural highs. The failure of other wells may result from no traps, poor entrapment or insufficient supply of hydrocarbon after destruction.

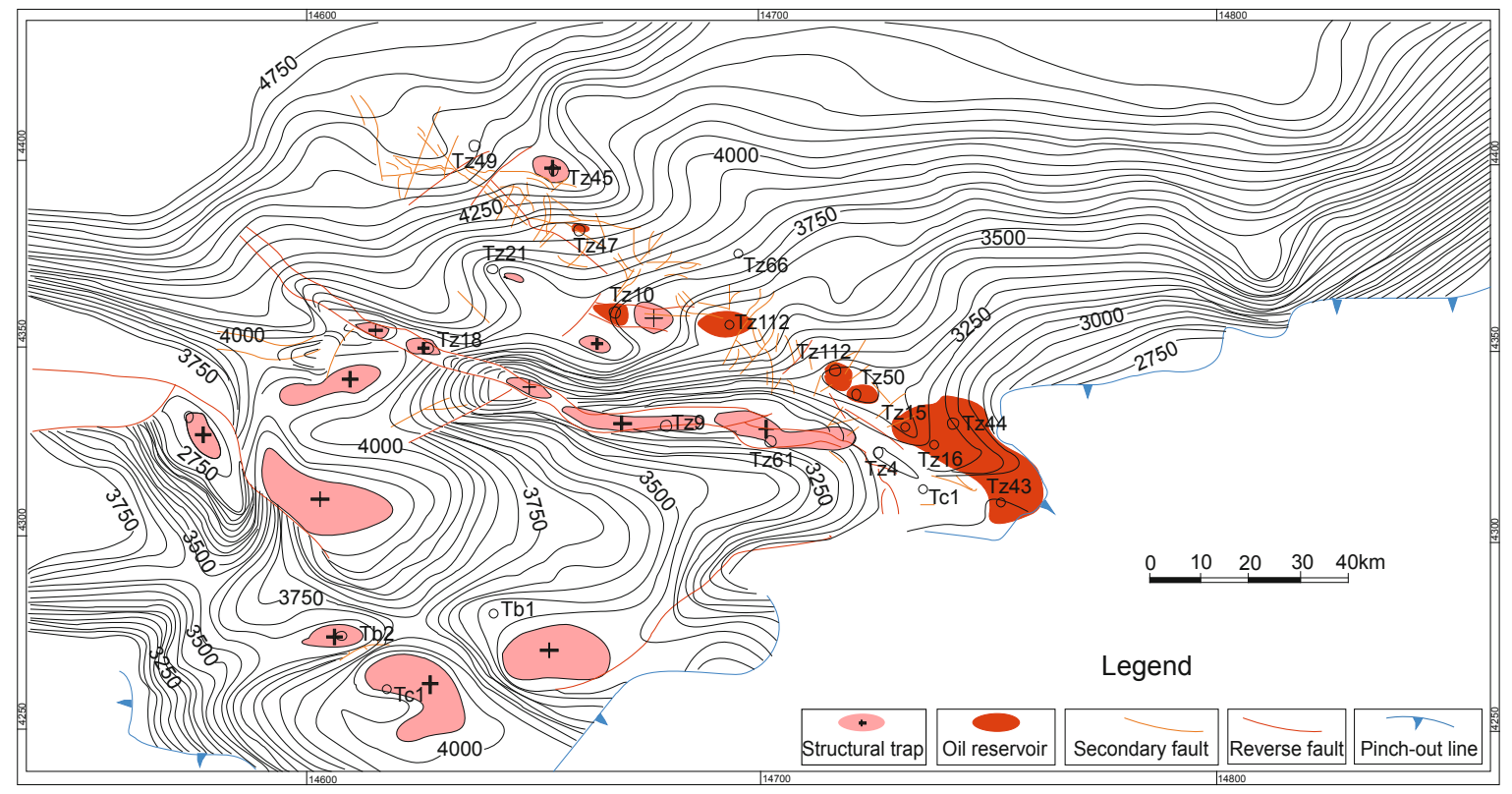

Fig. 6 Superposition map of the structure and reservoirs of the Silurian upper 3 sub-member in the central Tarim Basin

\subsection{Control of pressure energy on hydrocarbon accumulation}

Many scholars realize that the dynamic mechanism of hydrocarbon accumulation involves the fluid release caused by the breakdown of abnormal pressure compartments (Hunt, 1990; Hindle, 1997; Law and Spencer, 1998; Luo, 2004; Pang et al, 2000; Xie et al, 2004). Recent studies indicate that the migration and release of fluids in an overpressured system involves a kind of episodic breakage following the episodic opening of the fracture systems (Hao et al, 2002; Hao, 2005). The hydrocarbon generated from deep source rocks tends to have abnormal formation pressure. The fluids, after releasing pressure while moving upward along faults, will be distributed along the faults. The pressure release zones along the complicated faults then become favorable zones for hydrocarbon accumulation.

Recent studies also show that the Silurian hydrocarbon in the Tazhong Uplift originated from the deep Cambrian and Ordovician formations ( $\mathrm{Li}$ et al, 2008), with very complicated genesis because of multi-stage mixed source rocks. The formation period of the Silurian hydrocarbon includes the late Caledonian (i.e., the end of the Silurian), the late Hercynian (i.e., the Permian) and the YanshanHimalayan (mainly the Tertiary) ( $\mathrm{Hu}$ et al, 2005). The regional migration of the hydrocarbon formed in deep source rocks is controlled not only by structural stress, but also by abnormal formation pressure. A review of the hydrocarbon generation and expulsion history of source rocks in the Tazhong area, combined with the simulated result of pressure 
evolution in the Tazhong 1 Belt, indicates that the middle and lower Cambrian source rocks generated large amounts of hydrocarbon at the end of the Sangtamu sedimentary period, and then the overpressure decreased because of largescale expulsion of hydrocarbon. A simulated experiment of TC1-TZ62 shows that in the Hercynian period, the middle and lower Cambrian source rocks generated large amounts of gas while the middle and upper Ordovician source rocks generated large amounts of oil, again producing overpressure. On the cross section of Tazhong 1 Belt, the abnormal formation pressure, separated by faults, is discontinuously distributed. At the end of the Sangtamu and the Silurian, the tectonic movements on the two sides of the Tazhong 1 Belt were much more active than those in the middle. The frequent and intense faulting activities on the two sides make the overpressured fluids move vertically upward through the faults, with more energy released.

Studies also indicate that the horizontal distribution of reservoirs is closely related to faults ( $\mathrm{Li}$ et al, 2007). Good reservoirs in the formations adjacent to faults tend to display petroleum, which means that the hydrocarbon accumulation in the central Tarim Basin is controlled by both the NW and NE faults (Fig. 6). The hydrocarbon in this area first moved vertically into the Silurian sandstones through the footwall of the Tazhong 1 Belt, and then to the Donghe sandstones. Afterwards, hydrocarbon moved horizontally southward to the Tazhong 10 structural zone, and then began to turn eastward ( $\mathrm{Li}$ et al, 2005). A sag between the central fault horst belt and the Tazhong 10 zone made it impossible for the hydrocarbon to reach the western part of the central fault horst belt. The Silurian hydrocarbon in the Tazhong Uplift is mainly distributed adjacent to faults. Even the oil and gas in the lithologic reservoirs underwent the same migration process, i.e., they first entered into the sandstones through faults and then migrated laterally within the sandstones for accumulation. The overpressured fluids, led by faults, reached the Silurian clastic sandstones and accumulated in relatively low places with relatively high porosity and permeability. In this migration process, the hydrocarbon released its overpressure to be distributed in normal pressure zones (Fig. 7). Previous studies also show that an important reason why the hydrocarbon in the Silurian reservoirs are well preserved till now lies in the overlying caprocks, composed of red mudstones in the lower member of the Tataaiertage Formation and the lower Carboniferous red mudstones. Overpressure is well developed beneath these caprocks, especially in the lower Carboniferous red mudstones. For example, the Silurian fault-anticline reservoirs in the Tazhong 10 zone usually have normal pressure or weak overpressure. The poor compaction in the Carboniferous and Permian mudstones produced abnormal overpressure to seal the hydrocarbon cap, which made the bottom a relatively low-pressured pool, favorable for hydrocarbon accumulation (Fig. 7). Fig. 8 shows the remaining mudstone pressure in the Tazhong 30 well, which indicates that the pressure remaining in the Silurian reservoirs is relatively low while that in the overlying Carboniferous and the underlying Ordovician formations is high.

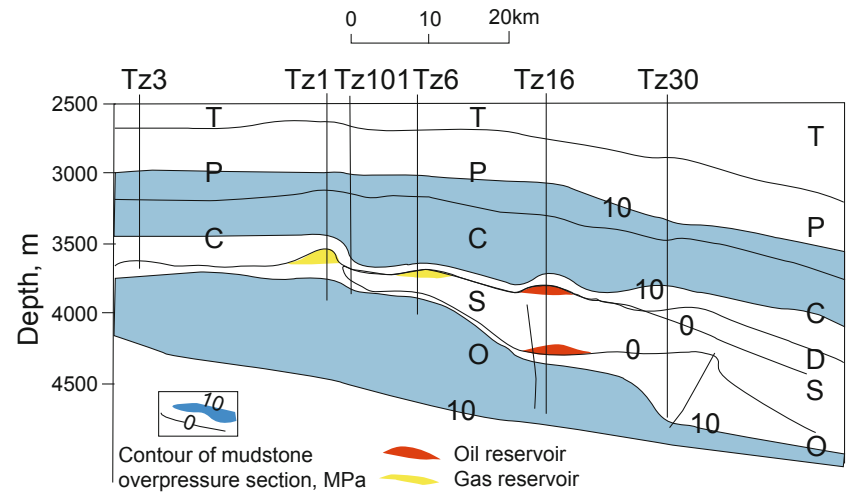

Fig. 7 Oil reservoir section and the distribution characteristics of overpressure in the TZ3-TZ30 well zone

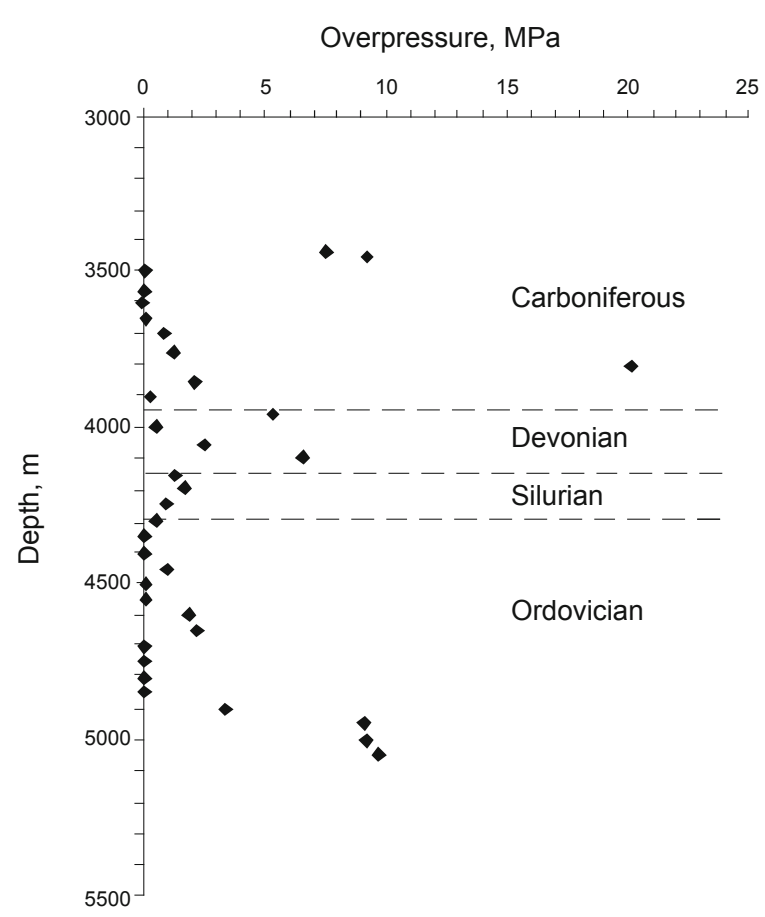

Fig. 8 Overpressure section of the TZ30 well

\section{Control of facies-potential on Silurian hydrocarbon accumulation in the Tazhong Uplift}

As analyzed above, the formation and distribution of Silurian reservoirs in the Tazhong Uplift are jointly controlled by facies and fluid potential. The former controls the macro time-space distribution while the latter dominates the micro petroleum occurrences. In the Dongying Depression, one of Chinese eastern sedimentary basins, over $90 \%$ of the discovered petroleum pools are developed in the traps with favorable facies and low potential, adjacent to source rocks. This means that a combination of favorable facies and low potential is the most favorable for hydrocarbon accumulation. In other words, the favorable facies and low potential jointly 
control hydrocarbon occurrences, i.e., the higher the FPI, the higher possibility the petroleum occurrences in the traps (Pang et al, 2007; Chen et al, 2008).

For the Silurian Formation in the central Tarim Basin, relatively high porosity and relatively low potential are favorable for the formation of reservoirs. Therefore, we use the homogenization method to establish a favorable facies index $(F I)$ and a low potential index $(P I)$, as shown in Eqs. (1) and (2). FI is a function of the relative values of reservoir porosity and permeability. A higher value of the FI suggests a better reservoir which is more favorable for hydrocarbon accumulation and more likely to become a petroleum pool.

$$
F I=\left(\phi / \phi_{\max }+K / K_{\max }\right) / 2
$$

where, FI is the relative facies index, dimensionless; is the reservoir porosity, \%; $\max _{\text {ax }}$ is the possible maximum reservoir porosity under local geological conditions at the same depth as the reservoir, $\% ; K$ is the reservoir permeability, $10^{-3} \mu \mathrm{m}^{2}$; $K_{\max }$ is the possible maximum reservoir permeability under local geological conditions at the same depth as the reservoir, $10^{-3} \mathrm{\mu m}^{2}$.

The relative potential index $(P I)$ is used to measure the control of potential energy on the hydrocarbon accumulation. As a relative concept, the value of $P I$ ranges from 0 to 1 . A lower value of $P I$ (closer to 0 ) means the place is closer to the ground surface or at a local structural high, which is more likely to become an anticline reservoir. A higher value of PI (closer to 1) means the place is closer to the hydrocarbon source kitchen and without a local structural high, there is little possibility for an anticline reservoir to develop.

$$
P I=\left(P-P_{\min }\right) /\left(P_{\max }-P_{\min }\right)
$$

where, $P I$ is the relative potential energy index; $P$ is the potential energy within the reservoir, $\mathrm{J} ; P_{\min }$ is the potential energy at the top or bottom of the hydrocarbon source kitchen, $\mathrm{J} ; P_{\max }$ is the potential energy at the ground surface, J. The facies-potential index $(F P I)$ can be expressed as Eq. (3).

$$
F P I=\frac{1}{\sqrt{2}} \sqrt{F I^{2}+(1-P I)^{2}}
$$

where, FPI is the facies-potential index, ranging from 0 to 1 , dimensionless; FI is the favorable facies index, ranging from 0 to 1 , dimensionless; $P I$ is the low potential index, ranging from 0 to 1 , dimensionless.

Statistics show that the discovered petroleum pools and wells producing commercial oil in the Silurian Formation of the central Tarim Basin are mostly located in the place where the $F P I>0.5$ while over $60 \%$ unsuccessful wells are located in the place where the FPI is less than 0.5. A failure in this area may result from the low FPI, i.e., a low probability of reservoir formation, and other causes also exist. For example, an unsuccessful well may be too far away from faults or may not encounter a reliable trap in a structural high. Therefore, favorable targets for exploration may be predicted by studying a map of FPI horizontal distribution and choosing places near the faults with an FPI value higher than 0.5 , and where traps for undiscovered petroleum pools may exist. The higher the FPI value is, the higher the possibility of

\begin{tabular}{|c|c|c|c|c|c|c|c|}
\hline Well No. & $\begin{array}{c}\text { Average } \\
\text { depth }\end{array}$ & $\begin{array}{c}\text { Porosity } \\
\%\end{array}$ & Interpretation & $\begin{array}{l}\text { Maximum } \\
\text { porosity, \% }\end{array}$ & $F I$ & $P I$ & $F P I$ \\
\hline tz24 & 3841.5 & 6.17 & Water & 19.18 & 0.32 & 0.51 & 0.41 \\
\hline tz44 & 4191.5 & 9.47 & Oil & 16.87 & 0.56 & 0.56 & 0.50 \\
\hline tz62 & 4215.5 & 9.6 & Oil & 16.72 & 0.57 & 0.56 & 0.51 \\
\hline tz161 & 4218 & 10.9 & Oil & 16.71 & 0.65 & 0.56 & 0.56 \\
\hline tz72 & 4271 & 11.15 & Water & 16.38 & 0.68 & 0.57 & 0.57 \\
\hline tz 80 & 4345 & 8.08 & Water & 15.92 & 0.51 & 0.58 & 0.47 \\
\hline tz69 & 4348 & 9.46 & Oil & 15.90 & 0.59 & 0.58 & 0.52 \\
\hline tz821 & 4357 & 10.48 & Water & 15.85 & 0.66 & 0.58 & 0.55 \\
\hline tz825 & 4360 & 8.83 & Water & 15.83 & 0.56 & 0.58 & 0.49 \\
\hline tz 50 & 4362 & 9.34 & Oil & 15.82 & 0.59 & 0.58 & 0.51 \\
\hline tz12 & 4375 & 9.17 & Oil & 15.74 & 0.58 & 0.58 & 0.51 \\
\hline tz82 & 4393 & 8.47 & Water & 15.63 & 0.54 & 0.59 & 0.48 \\
\hline $\mathrm{zg} 7$ & 4394 & 9.72 & Water & 15.63 & 0.62 & 0.59 & 0.53 \\
\hline tz84 & 4404.5 & 8.88 & Water & 15.56 & 0.57 & 0.59 & 0.50 \\
\hline tz11 & 4411 & 9.58 & Oil & 15.52 & 0.62 & 0.59 & 0.52 \\
\hline tz15 & 4425 & 9.62 & Oil & 15.44 & 0.62 & 0.59 & 0.53 \\
\hline zg41 & 4501 & 6.04 & Water & 14.99 & 0.40 & 0.60 & 0.40 \\
\hline tz37 & 4680.5 & 11.45 & Water & 13.96 & 0.82 & 0.62 & 0.64 \\
\hline tz47 & 4989 & 13.1 & Oil & 12.27 & 1.07 & 0.67 & 0.79 \\
\hline tz85 & 5068 & 5.52 & Water & 11.85 & 0.47 & 0.68 & 0.40 \\
\hline
\end{tabular}
petroleum occurrences.

Table 1 FPI values in the Silurian Formation of the central Tarim Basin

\section{Prediction of favorable targets for exploration}

The places where the FPI in the Silurian asphalt-sandstone in the central Tarim Basin exceeds 0.5 are distributed in the following zones: Tazhong 45, Tazhong 47, Tazhong 21-18, Zhonggu 3-Tazhong 62, and Tazhong 11-50 and southward areas. Over $90 \%$ of the discovered reservoirs are located in the predicted zones, so it can be concluded that the prediction of favorable targets is reliable. On the basis of above analysis, two more favorable targets for future exploration in the Silurian asphalt-sandstone are predicted, i.e., south of the Tazhong 62 well in the Tazhong 1 Belt and south of the Zhonggu 5 well in the Tazhong 10 Belt on the northern slope of the Tazhong Uplift (Fig. 9).

\section{Conclusions and suggestions}

1) The Silurian hydrocarbon distribution in the Tazhong Uplift is controlled by structural facies and sedimentary systems at the macro level. At the micro level, the hydrocarbon occurrences are controlled by 


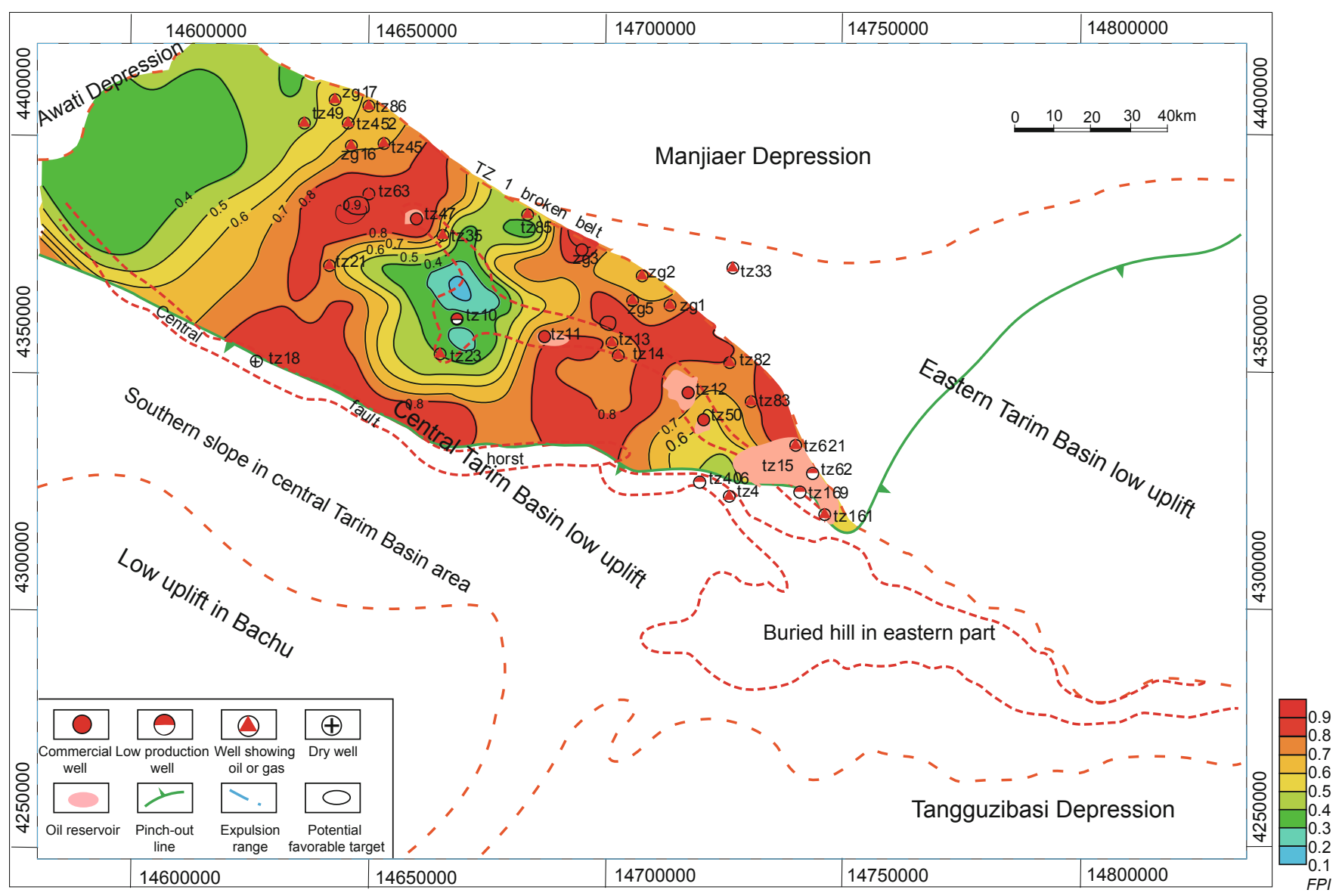

Fig. 9 The map of favorable facies and low potential of Silurian asphalt-sandstone and the prediction of favorable targets in the central Tarim Basin

lithofacies and petrophysical facies, which means high porosity and permeability may lead to good oil-bearing property. Relatively high porosity and permeability control hydrocarbon accumulation.

2) The Silurian hydrocarbon distribution in the Tazhong Uplift is also controlled by relatively low potential at local structural highs. Most successful wells are located at a local structural high, and places with relatively low potential show good oil-bearing property. The hydrocarbon distribution in this area is closely related to faults, and the favorable reservoirs close to the faults all show good oil-bearing property.

3) The Silurian hydrocarbon accumulation mechanism in the Tazhong Uplift can be described as follows. Induced by structures, the deep and overpressured fluids migrated through faults into the sand bodies with relatively low potential and high porosity and permeability. The released overpressure expelled the oil and gas into the normal-pressured zones, and the hydrocarbon was preserved by the overlying caprock of poorly compacted Carboniferous and Permian mudstones.

4) The Silurian hydrocarbon accumulation in the Tazhong area shows the characteristics of favorable facies and low potential. By establishing a relationship between oil-bearing property in traps and FPI, two favorable targets were predicted, i.e., south of the Tazhong 62 well in the Tazhong 1 Belt and south of the Zhonggu 5 well in the Tazhong 10 Belt on the northern slope of the Tazhong Uplift.

\section{Acknowledgements}

This study was funded by National Natural Science Foundation Programs of China (Grant No.40802029 and No. 41072100) and 973 Program (Grant No.2006CB209108).

\section{References}

Berg R R. Capillary pressures in stratigraphic traps. AAPG Bulletin. 1975. 59(5): 939-956

Chapman R E. Effects of oil and gas accumulation on water movement. AAPG Bulletin. 1982. 66(3): 368-378

Chen D X, Pang X Q, Zhang S W, et al. Control of facies / potential on hydrocarbon accumulation: a geological model for lacustrine rift basins. Petroleum Science. 2008. 5(3): 212-222

Dahlberg E C. Applied Hydrodynamics in Petroleum Exploration. New York: Springer-Verlag. 1982

England W A, Mackenzie A S, Mann D M, et al. The movement and entrapment of petroleum fluids in the subsurface. Journal of Geological Society, London. 1987. 144(2): 327-347

Gressly A. Observation geologiques sur le Jura Soleurois. Neue Denkschr. Allg. Schweiz. Ges. Naturw. 1838. 2: 1-112

Hao F. Hydrocarbon Generation Kinetics and Hydrocarbon Accumulation Mechanisms in Overpressure Basins. Beijing: Science Press. 2005. 137-238 (in Chinese)

Hao F, Zou H Y, Ni J H, et al. Evolution of overpressured systems in sedimentary basins and conditions for deep oil/gas accumulation. 
Earth Science-Journal of China University of Geosciences. 2002. 27(5): 610-614 (in Chinese)

Hindle A D. Petroleum migration pathways and charge concentration: a three dimensional model. AAPG Bulletin. 1997. 81(9): 1451-1481

Hsu K J. The concept of tectonic facies. Bulletin of Technique University Istanbul. 1991. 44(2): 25-42

Hu J F, Lü X X, Zhao F Y, et al. Controlling factors on petroleum accumulation in Silurian reservoirs in the Tazhong Uplift of the Tarim Basin. Acta Sedimentologica Sinica. 2005. 23(4): 734-739 (in Chinese)

Hubbert M K. Entrapment of petroleum under hydrodynamic condition. AAPG Bulletin. 1953. 37(8): 1954-2026

Hunt J M. Generation and migration of petroleum from abnormally pressured fluid compartments. AAPG Bulletin. 1990. 74(1): 1-12

Law B E and Spencer C W. Abnormal pressure in hydrocarbon environments. AAPG Memoir 70. 1998. 1-11

Levorsen A I. Geology of Petroleum (2nd Edition). San Francisco: W H Freeman. 1967. 47-494

Li M X, Dai Z Y and Li J. A hydrocarbon migration model of the Tazhong area, Tarim Basin. Henan Petroleum. 2005. 19(1): 1-10 (in Chinese)

Li S M, Pang X Q, Yang H J, et al. Characteristics and genetic type of the oils in the Tazhong Uplift. Earth Science-Journal of China University of Geosciences. 2008. 33(5): 635-642 (in Chinese)

Li Y P, Chen L X, Wang Y, et al. Main controlling factors of Silurian reservoir migration and accumulation in the central Tarim Basin. Chinese Science Bulletin. 2007. 52(S1): 185-191 (in Chinese)

Liu C X, Qian L and Deng G Z. Dominant controlling factors and regularities of formation of petroleum accumulations in the Tazhong area. Journal of Geomechanics. 2007. 13(4): 355-367 (in Chinese)

Luo X R. Allogenic overpressuring associated with faulting and geological consequences. Acta Geologica Sinica. 2004. 78(5): 641647 (in Chinese)

Lü X X and Hu X. Hydrocarbon accumulation and distribution in the Tazhong low uplift of the Tarim Basin. Oil \& Gas Geology. 1997. 18(4): 288-308 (in Chinese)

Lü X X, Bai Z K and Zhao F Y. Hydrocarbon accumulation and distributional characteristics of the Silurian reservoirs in the Tazhong Uplift of the Tarim Basin. Earth Science Frontiers. 2008. 15(2): 156166 (in Chinese)

Miall A D. Principles of Sedimentary Basin Analysis (2nd Edition).
Springer-Verlag. 1990. 133-212

Pang X Q, Jin Z J and Zuo S J. Dynamics, models and classification of hydrocarbon accumulations. Earth Science Frontiers. 2000. 7(4): 507-513 (in Chinese)

Pang X Q, Li P L, Zhang S W, et al. Control of facies-potential coupling on hydrocarbon accumulation in continental faulted basins and its basic geological models. Oil \& Gas Geology. 2007. 28(5): 641-663 (in Chinese)

Robertson A H F. Role of the tectonic facies concept in orogenic analysis and its application to Tethys in the eastern Mediterranean Region. Earth Science Reviews. 1994. 37(3-4): 139-213

Spain D R. Petrophysical evaluation of a slope fan/basin-floor fan complex: Cherry Canyon Formation, Ward County, Texas. AAPG Bulletin. 1992. 76(6): 805-827

Sun L D, Li Y J, Jiang T W, et al. The central Tarim lower uplift: a composite hydrocarbon accumulation play in the Tarim Basin, NW China. Chinese Journal of Geology. 2007. 42(3): 402-423 (in Chinese)

Wang Z L and Chen H L. The distribution characteristics of formation pressure in the Manjiaer Depression and its adjacent area, Tarim Basin. Northwestern Geology. 1998. 28(3): 233-238 (in Chinese)

Xie X N, Liu X F, Zhao S B, et al. Fluid flow and hydrocarbon migration pathways in abnormally pressured environments. Earth ScienceJournal of China University of Geosciences. 2004. 29(5): 589-594 (in Chinese)

Xiong Q H, Peng S M and Huang S W. A preliminary study of the new concept of petrophysical facies and its initial application in the Lengdong-Leijia region in the Liaohe Depression. Acta Petrolei Sinica. 1994. 15(S1): 68-76 (in Chinese)

Xu J H, Cui K R and Shi Y S. A new model of tectonic facies and orogeny of back-arc collision. Journal of Nanjing University (Natural Sciences). 1994. 30(3): 381-389 (in Chinese)

Zhao W G, Peng S M, Cai Z X, et al. Stratigraphical sequence, sedimentary characteristics and reservoir distribution of the Silurian in the central Talimu Basin. Journal of Xi' an Shiyou University (Natural Science Edition). 2007. 22(1): 12-16 (in Chinese)

Zhou X Y, Yang H J, Wu G H, et al. The experiences and targets for exploration for large oil-gas fields in the Tazhong area, Tarim Basin. Xinjiang Petroleum Geology. 2009. 30(2): 149-152 (in Chinese)

(Edited by Hao Jie) 